\title{
The Valorisation of African Languages and Policies in the African Education Systems: A Case of Uganda
}

\author{
Michael Muzoora ${ }^{1, *}$, Daniel R Terry ${ }^{2}$, Agatha A Asiimwe ${ }^{1}$ \\ ${ }^{1}$ Faculty of education, University of Tasmania, Launceston, 7250, Tasmania, Australia \\ ${ }^{2}$ University Department of Rural Health, University of Tasmania, Launceston, 7250, Tasmania, Australia \\ *Corresponding Author: Michael.Muzoora@utas.edu.au
}

Copyright (C) 2014 Horizon Research Publishing All rights reserved.

\begin{abstract}
This paper highlights the challenges of current language policies in education in Africa, with reference to Uganda. Also examined are the likely challenges to language policy in education, while indicating how these challenges can be curtailed or overcome. The authors suggest a different view is required when approaching this topic with a paradigm shift from modernist theories imbued with colonial and neo-colonial approaches experienced by African countries over decades. The use of a more post-modernist critical theory is required to envisage democracy, linguistic justice, linguistic human rights, linguistic citizenship, diversity and sustainability for quality education and development. The execution of outdated language policies in education that are often misguided and do not reflect reality continually cost individual learners and their societies. This is evidenced by the trend of education output and research by scholars worldwide on literacy and educational achievement in Africa. Many African governments are tending towards local/arterial languages in educational policy and are supportive of inclusion of African languages in education; however the trend in literacy and educational attainment is stagnant with outcomes becoming worse. By advocating for a much wider collective approach, research based on these very communities by African researchers working with and in the communities can aid an improved outcome in the African settings. The approach advocates language policies in education to shift from borrowing colonial policies to pragmatic policies which are emancipatory and liberative with learner centred approaches to teaching and learning.
\end{abstract}

Keywords Africa, Linguistics, Hegemony, Literacy, Mother Tongue, Policy

\section{Introduction}

Most African government education systems have their roots from the colonial period.[1-6] Uganda's formal education system was introduced by the Christian missionaries in the 1800 s and to date some of the education polices still claim their roots from the colonial era and promises of modernity.[7, 8] As such, most educational policies have not broken away from this ideological entanglement of the past. Thiongo [9] affirms this when he acknowledges that African scholars and writers remain trapped by the colonial era of language. African governments continue to promote policies which do not connect with the realities of the societies. The policies continue to recreate and maintain the status quo, marginalise and discriminate the 'other' languages and communities.[7]

As most European and Asian countries look to revitalising their local languages, African countries still only provide lip service. African languages in education are still observed as factors of disunity, a cause for conflict with no place for African languages in education. To others, the venture is impossible and too expensive to undertake. It is felt that nature of the minority Ugandan languages cannot provide for a single local language to unite the various cultural groups for use as both a national and language of instruction in schools.

To mitigate ethnic conflict and to promote unity, African Governments have continually used language as a political or ideological tool of control. This makes foreign languages, such as English, in Uganda the official and medium of instruction, except in rural lower primary classrooms (P1-P3). In these areas the medium of instruction is 'mother tongue' or area language. Hegemonic forces have also prevailed in suppressing any break through to liberate these language policies. This has been achieved through the execution of structural violence of assimilationist policies which sustains the status quo by elite, publishers, funders like World Bank and IMF and educational authorities. [3, 10, 11] This political control and influence of the hegemonic forces have perpetuated increased threat of extinction of these languages, continued use of global languages like English in education as medium of instruction [12, 13]; increasing levels of illiteracy; and increasing levels of dropout rates and enormous cost (waste and expenditure) on both learners and economically. $[1,14,15]$ The political and economic considerations of language policies in education have overshadowed the intensity of social, psychological and 
pedagogical considerations.

If the African countries look to being positive contributors to this global age rather than victims of it, there needs to be change. There is a need for an ideological paradigm shift from language policies in education that emanate from colonial and neo colonial ideologies to those that target decolonisation and empowerment. [16] This shift needs to be where the local languages are seen not as opposing each other but as complimentary and empowering especially considering that in the African context, different languages play different functions, relatively share cultural underpinnings and that most African communities are multilingual. Hence, upholding the aspect of differences of value and the value of difference. [7]

\section{Background}

Uganda is a multi-ethnic and multilingual country with over 40 ethnic groups. About 13 of these are the major groups which account for approximately $80 \%$ of the population. The remaining 20\%; comprised of African, Europeans, Asians, and Arabs. The language considered to be dominant is Luganda and is native to only $16 \%$ of the population, although about $50 \%$ of the population have the ability to use it.[17] Even with this linguistic advantage, an official status for this language is still a matter of contestation. English and Swahili are still the recognized official languages though both languages are foreign in Uganda.[18]A lot of emphasis is attached to Swahili by the government since it is looked upon as instrumental in the integration, successful function and unification of the East African community.[19, 20] However, the populace have not been prepared to accept it with its advantages especially as Uganda is building upon a national language policy that supports trilingualism (foreign language, regional and local language fluency and proficiency).[18]

The Ugandan language policy in education identifies 36 mother tongues or arterial languages to be used for education purpose in the rural areas of Uganda from grade 1 to grade 3 with transition to English at grade 4. However, in instances where a number of languages prevail in a community an area language is used. The area languages are in most cases second languages to some minority groups and mother tongue to larger groups of the population though they do not cover the whole country [17], as shown in Table 1. While in urban areas English is the only medium of instruction throughout primary school level. $[8,18,21]$

\section{Context}

In the discussion of this paper the intentions are not to discredit foreign languages in education and English in particular, the authors still hold the importance of English especially for its role in today's globalised world. However desire to highlight that other African languages in particular mother tongues/first languages need the same space for effective functioning and participation within African societies at local regional and global levels. The issue raised here is the continued use of unfamiliar language to learners as a medium of instruction when research and practice has shown the negative consequences of subtractive education in the transcending decades in academia because of its pedagogic, linguistic and psychological barriers.[1, 3, 22-24] Conversely, similar studies have also attested to the positive results of using mother tongue as a medium of instruction. [1, $12,25-28]$

The reality however is that the very situations keep oscillating, African governments continue shifting to and from local languages as well as foreign languages as medium of instruction. It has been alluded to that learners have been used as 'Guinea pigs' in this trial and error process for decades with disastrous consequences and no consideration of their rights. [10, 27, 29] This is affirmed by Ndoleriire [24] when he asserted that

Otherwise how does one expect a Ugandan child in a Ugandan environment, to grasp a language which is a product of a totally alien culture, have enough mastery of it, to be able to understand the different disciplines at school, to compete with a native speaker who is taught in that language in his/her own environment and better still, to be creative and innovative in that language?

Skutnabb-Kangas [27] have attested this to be a violation of human rights which is tantamount to crimes against humanity and linguistic genocide.

Table 1. Showing a summary of the language policy in Rural Primary schools

\begin{tabular}{cccccccc}
\hline \multicolumn{2}{c}{ Languages } & \multicolumn{7}{c}{ Primary school class } \\
\hline $\begin{array}{c}\text { Local } \\
\text { language } \\
\text { English }\end{array}$ & $\mathrm{MI}+\mathrm{S}$ & $\mathrm{MI}+\mathrm{S}$ & $\mathrm{MI}+\mathrm{S}$ & $\mathrm{MI}+\mathrm{S}$ & $\mathrm{S}$ & $\mathrm{S}$ & $\mathrm{S}$ \\
Kiswahili & $\mathrm{S}$ & $\mathrm{S}$ & $\mathrm{S}$ & $\mathrm{MI}+\mathrm{S}$ & $\mathrm{MI}+\mathrm{S}$ & $\mathrm{MI}+\mathrm{S}$ \\
\hline
\end{tabular}

Key: MI-Medium of Instruction; S-Subject; P1-7-Primary Level, 1-7 Source: Uganda Primary School Curriculum: Volume Two (2000, P. 284)

This lack of trust and strong radical doubt in what is needed to offset the dilemmas of language in education with no ready-made solutions continue to loom in Africa. This is common knowledge, particularly in Uganda after the introduction and implementation of a language policy under the government white paper in 1992 [18] and 2000 respectively. [30, 31] Consecutively, even with increased government support signified by president Yoweri Museveni's ('1986' to 'date') involvement by writing a local language dictionary [32], reported increasing levels of low literacy levels are a common and indebted phenomenon. This is also characteristic of most African nations. [33]

The 2012 UNESCO report entitled 'Global education digestive', revealed that worldwide Sub-Saharan Africa ranks the highest for school drop outs, with $42 \%$ of pupils 
that drop out of school early without reaching the highest primary level. This accounts for a total of 11.07 million children. Within this ranking, Uganda ranks second highest with approximately $68 \%$ of the children that do not complete the primary cycle. [14] Under a project run by Uganda National Examinations board, called the National assessment of progress in education (NAPE) 1999, 2003, the statistics revealed that literacy levels are still low amidst the use of local languages in education. [34]

The 2012 Uwezo report on national assessments in Kenya, Uganda and Tanzania showed that a large numbers of children lack the competencies expected to have been developed after primary school. In addition, many are unable to read and count at a standard 2 level which reflects that schooling is not translating into learning. Results of the report show that two in every 10 children in Standard 7 in East Africa do not have Standard 2 level literacy and numeracy competencies. More to this, two out of every three pupils enrolled at Standard 3 level in East Africa fail to pass basic tests in English, Kiswahili or numeracy set at the Standard 2 level. The report reveals further that improvements in basic literacy and numeracy occur only slowly as children progress through the education system. This implies that the quality of learning remains low throughout primary school system. [15, 35]

According to the UWEZO report access to education in the three East African countries has expanded, while the quality of education has stagnated and may in fact have deteriorated further. Specifically, a little less than one in three children were able to pass the Kiswahili (32\%) and numeracy tests (29\%), but only one in six passed the English test $(16 \%)$. Similarly, less than one in six were able to pass both the literacy and numeracy tests combined (15\%). These results imply that the vast majority of pupils are not acquiring basic competencies during the early years of primary school as expected in the national curricula. [15, 35]

These issues are not as a result of language alone as there are other factors which are influential to impact on the literacy levels and educational attainment. However language is viewed as a major influence on the above occurrences. With these less than desirable trends outlined above, children in Africa, particularly in Uganda, it is not abnormal to find who are affected by the system. To illustrate this two scenarios are provided below: "James is approaching 12 years, but he can hardly utter a word in his mother tongue, Lusoga but he is fluent in English" [Urban primary pupil]. ["Jane is approaching 12 years, but can hardly read or write in English or mother tongue" Rural primary pupil]. [36]

The above scenario depicts the continued results of research reports on the state of primary school children with particular reference to Uganda. In James' situation, as an urban scholar, it is felt he is 'better off', however to others it is a double edged dilemma, as both Jane and James scenarios raise concerns of deficiencies in English, mother tongue/ area or both. [15, 33, 37]

In this respect, African nations continue to disregard children's rights as they continually impose irreparable damage to the children's development capabilities, perpetual poverty and long term harm to mental health. $[10,24,27,28$, $38,39]$ The major concern is why amidst the informative current research and government support, these results continue to show deficiencies. More so, why even in those that have adhered to mother tongue medium instruction continue to witness similar or even worse outcomes in terms of dwindling low levels of literacy and educational attainment. Against this background on dilemmas in literacy and educational attainment and the context of African languages it is pertinent to relate the two to the policy that brings them together as a basis for seeking solutions to these dilemmas.

\section{Whose Policy Is It?}

We start by asking whose policy is it, because it is intended to be in the interests of the nation's children and incorporation of their rights to full attainment of literacy and education but instead it appears to do the opposite. So whose policy is it? It can be argued that as much as policy has been revised to include mother tongue (GWP 1992), the policy remains ambiguous, unclear and not a well laid out language policy. This phenomenon is characteristic of many African nations.[26, 40]

In the Ugandan context, the policy was proposed by the Senteza Kajubi Educational policy review commission of 1987 and later incorporated in the Uganda government White paper of 1992. [18] Changes were further made in 1999 and 200/2002 with the introduction of a new curriculum which too held contradictions with no organised structures to support the development of local languages as mediums of instruction. [31, 41] This was followed by the introduction of a thematic curriculum by the ministry of education in 2007 but remains consistent with fraught due to ambiguity. The policy is still at the mercy and control of politicians, the elite and donors who tailor it to their own best intentions and orientations with minimal contributions of the relevant communities.[5] There is a need to revisit the language policy in Uganda by drafting one well-articulated and explicit laid out national language policy document for quality education and education for all to be realised. The policy must largely harbor the interests and participation of the communities as owners and users of these languages with involvement of other stakeholders as partners. Such approaches call for pragmatic language policies in education that base on cultural and ethnic roots to incorporate the understanding of local knowledges that are embedded in these languages, a majority of which are still oral, into the curriculum through intergenerational learning strategies. Such policies have to empower communities to use their knowledge base in teacher methodology and training that reflect their traditions and values rather than depending on western policies which are based on competition. Such approaches would encourage constructively aligned and 
purposive learning; improve the verbal and non-verbal skills; and greatly contribute to the cognitive and social development of the learners. It is through these policies that may provide emancipatory spaces for understanding, skills and capabilities that will enrich the learners with the appropriate literacy while promoting creative and inventive minds to support their communities.

First and foremost, good public policy, such as the language policy, should work towards addressing inequality and inequity issues in society rather than perpetuating marginalisation and discrimination. Skutnabb-Kangas [10] argues that schools mirror society, in that if there is existence of systematic inequality in society it is reflect and reproduced in school. A change of this systematic inequality therefore has to first and foremost be effected in the schools to effectively get entrenched in society. Pragmatic language policies in this instance would open the classroom doors to the community by involving indigenous knowledge holders as teachers, teacher trainers or/and teaching assistants. Such actors have the expertise concerning their language and culture and their community's needs and aspirations. Hence such collaborative approaches to teaching and learning among community, teachers and learners would promote quality relationships in communities, convert oral original knowledge based on their histories, own experiences and imaginations to written form. It would also adopt majority language materials to the local language and context as well as facilitating translation of materials from other languages into mother tongue. This is where the building of the social, economic and cultural capital would start to effectively change the systematic inequalities in these societies, sustain the languages and as a consequence the biodiversity.

The current language policy promotes unfairness access and use of language in education by denying the urban children their right to know and learn in and through mother tongue or area language. Denying a child's home language in the school is leaving a central part of who they are outside the school. [42] Local languages form a basis and the formation of an integral part of the philosophy of an individual since they hold the very essence of what defines ones humanity, their culture. In the African context, it also bridges the school and home learning by building from the known to unknown. Integrating local languages in school provide a greater foundation in learning/literacy. Learners perform better, with fewer repeating rates, fewer drop outs, more family support, while the cycle of exclusion and status quo are broken. [43] All learners' first language is the best in optimising learning for beginning literacy development, a foundation for transfer of linguistic and conceptual knowledge to a second language.

This also implies that languages are cultural packages, and more so, pillars of cultural systems which promote a sense of belonging, self-awareness and esteem. Having them integrated in the school will boost the education attainment by making students feel part of the space shared at the school. Hence, conservation of the language is ultimately the conservation of the culture which it entails. Restricting a child to a foreign language for education purpose is synonymous with child abuse and accelerates the killing of these languages. $[10,12]$ waThiong'o [44] has attributed this approach to enslavement on the part of those restricted to a foreign language for accessing education while exposure to mother tongue and other languages as emancipatory.Emancipatory in the sense that acquisition of these languages comes with varied knowledges, cultural packages and builds learners to have varied view points on their approach to life situations. Such approaches also build learners to appreciate and accommodate the views, interpretations, and ways of knowing of other communities hence developing a wider conceptual understanding and knowing. These learners will also not only offer similar respect to other languages but will also use the sharing of the languages to enrich the knowledge and experiences of others. Such pragmatic policies would promote quality community relations, social cohesion and a common sense of nationhood through feeling and oral expression. In a broader perspective such approaches would also promote better global citizens.

\section{English in Urban vs Mother Tongue and English in Rural, in Whose Interest?}

The fact that the language policy in rural and urban primary schools uses different approaches is an equity and equality dilemma in education. The argument used to justify this inequity is urban areas are multi-lingual and more complex due to diverse working population backgrounds and therefore necessitating consideration of the workers' children by opting for a submersion to English. [21] However, what is denied is the fact that the nature of the African community multilingual context is that people are able to speak and communicate sufficiently in more than one local language as a consequence of either migration and or urbanisation. Due to these occurrences some children in urban centres become more fluent in the area / community language at times than their first language or even English. They are bound to meet the area language in the community, play grounds, among peers as well as informally at school. As such language acquisition should not be seen as a deterrent but a benefit to the learner, community and country.

The various communities have greater familiar traditions and cultures compared to a foreign culture and language. In addition, it can be argued that native children could, in most cases, turn out to be the majority in these urban classroom settings. Hence, a call to revisit policy in such communities too and work towards promotion of the mother tongue/area languages for education purposes to the benefit of both first and second languagespeakers. [21]

The urban children can also be able to reap benefits of bilingualism, cognitively, culturally, socially and linguistically when taught in the mother tongue/ area language medium. This would lead to increased social 
returns to investment in education due to contextualised learning as well as community empowerment since the very products regardless of ethnic background would seek employment in all these areas and therefore attainment of this language potentially has an added advantage. The argument for English medium is therefore unrealistic, elitist and politically instigated. In reality the policy tries to protect the sons and daughters of civil servants while disadvantaging the native children who would benefit from using their local languages for instruction. [21] This effort by hegemonic forces and elite work to sustain the status quo and continue to perpetuate vicious cycles of marginalisation and discrimination of sections children and society while advantaging others. One would wonder, why similar situations that exist in rural schools where non-native learners share classes with native children are instructed through mother tongue and or area language but not given the same consideration for English medium. This affirms that the policy still harbors colonial and neo-colonial language policies. Incorporating mother tongue/ area languages guided by pragmatic policieswould also propagate national unity, social integration and a sense of patriotism among the learners since they will be able to see themselves beyond ethnic boundaries. The use of these languages by non-native speakers would not only foster social cohesion and a sense of belonging for the non-native speakers but also this increased number of diverse languages could be tapped by school. [45]

The approach would also establish a certain level of equity and equality balance between the rural and urban divide in terms of resource distribution in education since most parents would rather have their children learn through mother tongue rather than another local language. Hence looking towards advantaging the disadvantaged areas and consequently a redistribution of resources, this would ultimately reduce on the cost implications of the languages, enhance local publishing industry and increased language teachers who may not necessarily be native speakers. This would also ultimately lead to linguistic and bio diversity sustainability since it is in these local languages that bio diversity is conserved.

\section{Why Emphasis on English Medium from First Grade?}

The Ugandan language policy still harbors colonial language policies that adopt the use of local languages for the first lower classes of primary school or use of the foreign language from the first grades of school. The direct submersion to English as the first language is unrealistic, and in any case considering that it (English) could be a second or third language for most of these learners they would still encounter the effects of learning through a non-familiar language. Hence, many struggle to comprehend the English language and then using it as a medium for learning other subjects. This is because students are not able utilise the linguistic skills already developed in the first language and are denied the right to build from what they already know in their learning process. This is because some texts, teaching and learning materials used are still 'foreign'. This then positions the school language (English) as the legitimate language (power-relations), which causes a hegemonic influence that promotes symbolic capital, while inflicting social symbolic violence to the local learners and societies.

It can also be argued that if English submersion was pedagogically viable then children in urban schools would, over the years, have continually performed better in English and generally in the curriculum compared to the rural counterparts. However, this has not been the case. Therefore the aspect of time spent using the language as medium of instruction does not necessarily correlate to language competence as presumed. This is because it is influenced and impacted upon by other factors like quality of teachers and instructional resources. [45]

Another controversy is on the use of English medium by urban learners and mother tongue/area language by the rural learners yet sitting the same exams administered in English at the end of the primary cycle (P. 7.). This scenario is viewed by rural parents as a disadvantage to their rural children especially considering that they all compete for similar opportunities in the job market after school. This has made primary education 'exam oriented' and 'elitist' with the major goal to attain secondary education. As such, rural parents elect the English medium for their children which then influence the rural schools to keep on with English medium. It has encouraged what Freire [46] termed the banking concept of education where learners are not guided to wholesome educational development of psychomotor, affective and cognitive domains but concentrating on passing the final exam rather than comprehending what is taught. A consideration for policy is to incorporate continuous assessment in the teaching and learning approaches so as to improve literacy and educational attainment, but also cut on overwhelming government expenses of such exams. It may also liberate leaners as it would fit the learners in their societies through constructively aligning assessments to time and importance of intended learning outcomes and activities that are piece meal. Such an approach is not only a motivator to self-directed purposive learning but also looks at teachers and students as subjects who not only uncover knowledge, but recreate it through common reflection and action. [46] In this respect, continuous assessment was a recommendation by the 1987 education review commission, yet has never been implemented in the education assessment of primary learners.

\section{Colonial Fixation}

The policy recaptures aspect of area languages from a colonial approach. Initially, this policy is a replica of the 1963 policy on language in education by the Castle commission that was later adopted in 1965 . The 1965 policy 
added Runyakole/Rukiga to the five (5) area languages that were initially identified by the 1944 Makerere conference on language, where some languages like Luganda, were imposed on some groups or minority languages for colonial benefit.[47, 48]

At present, six area languages as we know them today are unable to play the functions the architects of the 1992 policy intended, since the intentions are very different from those of 1944. The six languages in reality can no longer be considered area languages anymore. For example, Luganda is no longer an area language as it was previously considered in the eastern part of the country. Historically, it is an imposed language on people of a different dialect but of the same language group. The Basoga no longer accept to be dominated by another ethnic group linguistically and have increasingly worked toward language awakening, developing the different areas of Lusoga language and culture. $[17,49]$ In addition, the presumed speakers of Lwo do not view themselves as a single unit of speakers. The Acholi and Langi are progressively working to develop their own languages. While the western Bantu languages of Runyankore/Rukiga, Runyoro/Rutoro have been curved into Runyakitara, a wider language of communication, but with some contestation among the different mother tongues that see their languages usurped under Runyakitara. [47] The aspect of six area languages in this colonial approach is therefore a myth which was imposed years ago.

It is therefore important to have clear language policies which provide opportunities to all mother tongues and area languages, yet viewed in ways to suit the times and needs of the various cultures and communities. Policies should not be used as instruments of oppression, but used as instruments of liberation. The mother tongues have to be developed overtime so that each of these communities keeps with its linguistic and cultural rights for self-determination and preservation at the lower levels but take the area languages for higher education purpose. By so doing, there is preservation of linguistic diversity, customs but also local knowledge and bio-diversity necessary for present and future existence.

\section{Area Languages in a New Lens, Harmonisation}

Prah [6], Prah and Town [50]proposes economically viable options for getting the African languages entrenched in African Educational systems. In their approach to this concept of harmonisation with the centre of advanced studies of African society CASAS), they draw on the works already done in harmonisation of some languages. For example the amalgamation of western Bantu languages of Runyankole/Rukiga, Runyoro/Rutoro into Runyakitara by Makerere University. Also pursuing this concept is the African academy of languages, under the support of African Union. This concept aims to provide advantages from international cooperation with support of donor organisations especially from the fact that most African languages are cross boarder speech forms and defy the colonially inherited boarders. Some of these languages are intelligible in varying degrees. They should corroborate with neighbouring countries with shared linguistic challenges to harmonise and standardise these languages into one; facilitate traditional information exchange to tackle the problems of globalisation; and develop new relations that identify and form common culture at broader levels.

This economic viability is seen in cross boarder publishing potentials for the African languages, broader cultural identity and a bigger voice for advocacy and self-determination. In this regard, the work done by Makerere on harmonisation of Bantu languages into Runyakitara cannot be underestimated. For example, Runyakitara now embraces Runyakore, Rutoro, Runyoro, Rukiga in Uganda, Ruhaya in Tanzania. This approach could also suit the other language dialects with well based research. These can be facilitated by a national language advisory board which remains non-existent at present. Hence, policy has to approach area languages in a lens that is adjusted to the present terms or situations. The advantages of these area languages is that they are cross boarder and therefore these advantages spill across borders in a sense that costs can be minimised through cross boarder printing and cross boarder translations.[6]

For example, as the world develops into a global village, regional federations merge such as The Southern African development Community (SADC) and the East African Development Community (EAC). These organisations then enjoy cross border benefits and further foster togetherness, common history and languages. They then become the strategic pillars of these federations. However, amidst all the mutual intelligibility and legibility among these languages, mother tongues should be rejuvenated to ensure they survive extinction.

\section{The Need for Policy to be Based on Current Developments in Research}

The policy should also consider current developments in research to avoid executing unyielding policies that inflict not only economic cost but also pedagogic and socio-cultural cost to governments. Many theories support mother tongue instruction and second language instruction. In addition they show that using a first language for instruction in the early years is pedagogically the best for meaningful learning to occur. Moreover research has shown that it is a vital tool for the proper development of the child, as well as a foundation for the development of a second language. The current available research has indicated that two to four years of mother tongue instruction is insufficient for educational attainment in the African context and that transferability skills from first to a second language cannot be attained. Alidou, Boly [1], Heugh [23], Heugh [38], Heugh, Benson [51], have indicated there are different bilingual approaches or models that are appropriate for Africa. Careful 
examinations of the existing research on language models for education which have been implemented are currently practised in Africa reveal that

- Six years of MTE (mother tongue education), followed by transition to a second language, can succeed under very specific and well-resourced conditions which are not readily visible in Africa.

- Eight years of MTE, followed by transition to a second or foreign language, can succeed under less well-resourced classroom conditions. Minimally 8 years of using mainly a mother tongue or an extremely well-known other language as the main medium of education, with good teaching of additional languages as subjects and with well-qualified minimally bilingual teachers can achieve the well required literacy and educational achievement of learners.

- MTE throughout primary followed by dual-medium education can work in situations where both languages are used by students in the local community, and where there are students from the two different language backgrounds in the same classroom.

- MTE throughout primary and secondary plus very well-resourced teaching of the second/international language as a subject may best prepare students for entry to university and the use of the international language as a medium of instruction in study beyond school (university, teacher training, etc.).

\section{Conclusion}

In a nutshell, the paper highlights that the African Governments continually digress from the realities in dealing with the challenges of current language policies in education in Africa, with reference to Uganda. It highlights the lack of trust and all-pervading radical doubt among African countries in what is needed to offset the dilemmas of language in education with no ready-made solutions. African governments continue to promote policies which do not connect with the realities of the societies and continue to recreate and maintain the status quo, marginalise and discriminate the 'other' languages and communities. The paper argues that African governments continue to advance political and economic considerations above the social, psychological and pedagogical considerations with disregard to children's rights as they continually impose irreparable damage to the children's development capabilities, perpetual poverty and long term harm to mental health. The major concern the paper addresses is why amidst the informative current research and government support for use of African languages in education, there are continued deficiencies and continued stagnation with worse outcomes in others in terms of dwindling low levels of literacy and educational attainment. The paper advances and discusses different Issues that influence the sustenance of such policies as well as some steps that can be taken to overcome such challenges. The paper concludes by advocating for a much wider collective approach of 'putting the last first', research based on these very communities by African researchers working with and in the communities can aid an improved outcome in the African settings. The approach advocates language policies in education to shift from borrowing colonial policies to pragmatic policies which are emancipatory and liberative with learner centred approaches to teaching and learning.

\section{REFERENCES}

[1] Alidou H, Boly A, Brock-Utne B, Diallo YS, Heugh K, Wolff HE, editors. Optimizing Learning and Education in Africa-the Language Factor. 2006.

[2] Brock-Utne B. African universities and the African heritage. International Review of Education. 1999;45(1):87-104.

[3] Brock-Utne B. Whose education for all?: The recolonization of the African mind: RoutledgeFalmer; 2000.

[4] Change CA, Evans DR, Kajubi WS. Education Policy Formation in Uganda. Education policy formation in Africa: a comparative study of five countries. 1994(12):127.

[5] Kabanze BM. Whose policy is it anyway: a study examining the factors that have influenced the formulation and reform of language-in-education policy (LiEP) in Zambia. 2012.

[6] Prah. Going Native: Language of Instruction for Education, Development and African Emancipation. In: Birigit Brock-Utne ZDaMQ, editor. Language of Instruction in Tanzania and South Africa (LOITASA). Dar-es-Salaam: E \& D Limited; 2003. p. 14-34

[7] Smith P, Riley A. Cultural theory: an introduction. Oxford: Blackwell Publishing; 2009.

[8] Muzoora M, Terry D. African higher education: The renaissance and reformation of language Innovative trends in language and literacy education in a global discourse 2013.

[9] Thiongo Nw. Makerere Dreams: Language and New Frontiers of knowledge. Speech given at the programme for the University of East Africa 50th anniversary celebrations on 29th June 2013, Main hall, Makerere University2013.

[10] Skutnabb-Kangas T, editor. The stakes: Linguistic diversity, linguistic human rights and mother tongue based multilingual education-or linguistic genocide, crimes against humanity and an even faster destruction of biodiversity and our planet. Keynote presentation at Bamako International Forum on Multilingualism, Bamako, Mali; 2009.

[11] w'Obanda CM. Africa: Struggle for the second liberation. Challenge of the 21st Century. Second ed. Kampala: Lusamia Association; 2011. 228 p.

[12] Skutnabb-Kangas T, editor. Language Policies and Education: the role of education in destroying or supporting the world's linguistic diversity. World Congress on Language Policies, Barcelona; 2002. 
[13] Tsang MC. Cost analysis for educational policymaking: A review of cost studies in education in developing countries. Review of educational research. 1988;58(2):181-230.

[14] UNESCO. Opportunities lost: The impact of grade repetition and early school leaving. Global Education Digest. Montreal, Quebec: UNESCO Institute for Statistics; 2012.

[15] UWEZO. Are our Children Learning? Literacy and Numeracy across East Africa. 2012.

[16] Agbedo CU, Krisagbedo EC, Eze VO. Mother Tongue Education as Agency of Decolonisation: Implications for National Development in Nigeria. Developing Country Studies. 2012;2(11):170-81

[17] Kate P. Language and Literacy in African Context. Language Matters: Studies in the Languages of Africa. 1999;30:1:113-30.

[18] Government of Uganda. The Government White Paper on the Education Policy Review Commission Report, Education For National Integration and Development 1992. . Entebbe: Uganda Publishing and Printing Corporation. ; 1992.

[19] Pawliková-Vilhanová V. Swahili and the dilemma of Ugandan language policy. Asian and African Studies. 1996;5(2):158-70.

[20] Mukuthuria M. Kiswahili and its expanding roles of development in East African Cooperation: A Case of Uganda. Nordic Journal of African Studies. 2006;15(2):154-65.

[21] Muzoora M, Terry D. Muddling through: A critical review of Ugandan language policy in education The Internet Journal of Language, Culture and Society. 2013; In press.

[22] Bamgboșe A. Language and exclusion: The consequences of language policies in Africa: LIT Verlag Münster; 2000.

[23] Heugh K. Into the cauldron: An interplay of indigenous and globalised knowledge with strong and weak notions of literacy and language education in Ethiopia and South Africa. Language Matters. 2009;40(2):166-89.

[24] Ndoleriire OK. Language, Culture and Development. Uganda's experience. In: University M, editor. Kampala: Makerere University; 2004.

[25] Zubeida D. A Case for Mother Tongue Education? In: Birigit Brock-Utne ZDaMQ, editor. Language of instruction in Tanzania and South Africa (LOITASA). Dar-es Salaam: E \& D Limited; 2003. p. 45-68.

[26] Spolsky B. Language policy failures-Why won't they listen? Essen: Linguistic Agency, University of Duisberg-Essen (LAUD). 2004.

[27] Skutnabb-Kangas T. Linguistic Genocide in Education--or Worldwide Diversity and Human Rights?: Routledge; 2013.

[28] Ouane A, Glanz C. Optimising Learning. Education and Publishing in Africa: The Language Factor. A review and analysis of theory and practice in mother tongue and bilingual education in sub-Saharan Africa. Hamburg: UNESCO Institute for Lifelong Learning, and Tunis Belvedere: Association for the Development of Education in Africa; 2011.

[29] Skutnabb-Kangas T. Human rights and language policy in education. In: Hornberger SMaN, editor. Language policy and political issues in education. 2nd Edition, Ed. ed. New york2008. p. 107-19.

[30] Ward M, Penny A, Read T. Education Reform in Uganda: 1997 to 2004: Reflections on Policy, Partnership, Strategy and Implementation: Department for international development (DFID); 2006.

[31] Altinyelken HK. Pedagogical renewal in Sub-Saharan Africa: the case of Uganda. Comparative Education. 2010;46:2:151-71.

[32] Naturinda S. "Katondoozi y'Orunyankore-Rukiga", a Thesaurus of the Runyankore-Rukiga dialect The Daily Monitor. 2012.

[33] SACMEQ. SACMEQ III Project Results: Pupil achievement levels in reading and mathematics. Southern and Eastern Africa Consortium for Monitoring Education Quality. 2010; Working Document 1.

[34] Higgins L, Rwanyange R. Ownership in the education reform process in Uganda. Compare: A Journal of Comparative and International Education. 2005;35(1):7-26.

[35] Sumra S, Mugo J. Are our children learning? Assessment of learning outcomes among children in Tanzania, Kenya and Uganda. 2012

[36] Nafula J. Uganda dialects endangered, says Makerere don. Daily Monitor. 2009.

[37] Benjamin P. Uganda Early Grade Reading Assessment Findings Report: Literacy Acquisition and Mother Tongue. Makerere University Institute for Social Research: RTI International; 2010.

[38] Heugh K. Contesting the monolingual practices of a bilingual to multilingual policy. English Teaching: Practice and Critique. 2009;8(2):96-113.

[39] Brock-Utne B. Language policy and science: Could some African countries learn from some Asian countries? International Review of Education. 2012:1-23

[40] Walshaw M, Anthony G. Policy implementation: Integrating the personal and the social. Mathematics Teacher Education and Development. 2007;8:5-22.

[41] Penny A, Ward M, Read T, Bines H. Education sector reform: The Ugandan experience. International Journal of Educational Development. 2008;28(3):268-85.

[42] Cummins J. Bilingual children's mother tongue: Why is it important for education. Sprogforum. 2001;19:15-20.

[43] UNESCO. Language Matters for the Millennium Development Goals. 2012.

[44] waThiong'o N, editor. Makerere Dreams: Language and new frontiers of knowledge. Speech given at the programme for the University of East Africa 50th anniversary celebrations on 29th June 2013; 2013; Makerere University.

[45] Benson C. How multilingual African contexts are pushing educational research and practice in new directions. Language and education. 2010;24(4):323-36.

[46] Freire P. Pedagogy of the Oppressed, trans. Myra Bergman Ramos New York: Continuum. 1970. 
[47] Bernsten J. Runyakitara: Uganda's 'New' Language. Journal of Multilingual and Multicultural Development. 1998;19(2):93-107.

[48] Kasozi A, Parry K. The failure to develop a national language in Uganda: A historical survey. Language and literacy in Uganda: Towards a sustainable reading culture. 2000:23-9.

[49] Nabirye M, De Schryver G-M. The Monolingual lusoga dictionary faced with demands from a new user category.
Lexikos. 2010;20(1):326-50.

[50] Prah K, Town C. The Language of Development and the Development of Language in Contemporary Africa. 2011.

[51] Heugh K, Benson C, Bogale B, Yohannes MAG. Final report: Study on medium of instruction in primary schools in Ethiopia. Ministry of Education, Ethiopia. 2007. 